\title{
Effect of progesterone on ovarian follicles, emergence of follicular waves and circulating follicle-stimulating hormone in heifers
}

\author{
G. P. Adams ${ }^{1 *}$, R. L. Matteri ${ }^{2}$ and O. J. Ginther ${ }^{1} \dagger$ \\ ${ }^{1}$ Departments of Veterinary Science; and ${ }^{2}$ Animal Science, University of Wisconsin, Madison, \\ WI 53706, USA
}

\begin{abstract}
Summary. The hypothesis was tested that greater growth of the dominant follicle of wave 1 (first follicular wave of an interovulatory interval), compared with that of subsequent anovulatory waves, is due to lower circulating concentrations of progesterone during the growing phase of the follicle. Control heifers $(n=6)$ were compared with heifers $(n=6)$ treated with a decreasing dose of progesterone from day 0 to day 5 (ovulation $=$ day 0$)$. Maximum diameter $(12.7 \pm 0.9$ versus $15.3 \pm 0.7 \mathrm{~mm})$ and mean diameter of the dominant follicle of wave 1, averaged over days, were smaller $(P<0.05)$ in the progesterone-treated than in the control group. Progesterone treatment did not suppress circulating follicle-stimulating hormone (FSH); but the second FSH surge was earlier, resulting in earlier emergence of wave 2 as indicated by a tendency $(P \leqslant 0 \cdot 1)$ for group $\times$ day interactions attributed to earlier detection of the dominant follicle and an earlier rise in the total number of follicles detected. The stated hypothesis was supported.

We also tested the hypothesis that exposure to low circulating concentrations of progesterone at the end of the growing phase of the anovulatory dominant follicle of wave 1 results in continued growth and prolonged maintenance of the dominant follicle. Heifers ( $n=6$ per group) were given a luteolytic dose of prostaglandin $F_{2 \alpha}$ $\left(\mathrm{PGF}_{2 \alpha}\right)$ on day 6 and treated with a low $\left(30 \mathrm{mg} \mathrm{day}^{-1}\right)$, physiological $\left(150 \mathrm{mg} \mathrm{day}^{-1}\right)$, or high $\left(300 \mathrm{mg} \mathrm{day}^{-1}\right)$ dose of progesterone on days 6 to 20 . Continued periodic emergence of anovulatory follicular waves occurred $(2 \cdot 1 \pm 0.0$ waves, $2.8 \pm 0.2$ waves, $3.8 \pm 0.3$ waves, respectively; $P<0.05$ ) until treatment was stopped (interovulatory intervals: $26.2 \pm 1.0,30.8 \pm 0.6$ and $40.3 \pm 1.7$ days, respectively; $P<0.05$ ). Compared with the physiological dose group, the growth of the dominant follicle was inhibited to a lesser degree in the low-dose group since it grew for longer $(P<0.05)$ and to a larger diameter $(P<0.05)$, and persisted for longer $(P<0.05)$. Prolonged dominance of this oversized $(>20 \mathrm{~mm}$ ) follicle was associated with delayed emergence of wave 2. The hypothesis was supported. Results also showed that the high dose of progesterone suppressed the dominant follicle more than the physiological dose when given during the growing phase, but not when given after the growing phase. The suppressive effects of progesterone were not mediated by decreased circulating $\mathrm{FSH}$, since progesterone treatment did not suppress FSH. Collectively, the results demonstrated that progesterone inhibited the dominant follicle in a dose-dependent manner when the follicle was exposed during its growing phase.
\end{abstract}

Keywords: progesterone; follicle-stimulating hormone; follicles; follicular waves; ultrasound; cow

*Present address: Department of Veterinary Anatomy, Western College of Veterinary Medicine, University of Saskatchewan, Saskatoon, Saskatchewan, Canada S7N 0W0.

$\doteqdot$ Reprint requests to O. J. Ginther. 


\section{Introduction}

It has been known for over four decades that administration of progesterone alters ovarian function in cattle and, in sufficient doses, inhibits ovulation (Christian \& Casida, 1948; Trimberger \& Hansel, 1955). Because of technological limitations, however, the specific effects of progesterone on follicle growth, regression and wave development were not elucidated in the early studies. Recent studies involving transrectal ultrasonic imaging of the ovaries have clearly documented that follicular growth in cattle occurs in waves during the oestrous cycle (Pierson \& Ginther, 1988; Savio et al., 1988; Sirois \& Fortune, 1988; Knopf et al., 1989) and during early pregnancy (Ginther et al., 1989b). These studies have demonstrated that two or three waves occur during an oestrous cycle and that each wave consists of a dominant follicle and subordinates. An inverse relationship between progesterone concentration and diameter of the dominant follicle of a wave has been suggested by the following recent results: (i) in three-wave oestrous cycles, the maximum diameter of the dominant anovulatory follicle was greater for the first wave after ovulation (wave 1; under minimal luteal dominance during its growing phase) than for wave 2 (under maximum luteal dominance) (Sirois \& Fortune, 1988; Ginther et al., 1989c); (ii) the maximum diameter attained by the dominant anovulatory follicle was greater for wave 1 than for all subsequent waves in pregnant (Ginther et al., 1989b) and unmated progesterone-treated heifers (Bergfelt et al., 1991); and (iii) high concentrations of progesterone (endogenous plus exogenous) resulted in a smaller maximum diameter of the dominant follicle of wave 2 compared with subsequent waves (exogenous progesterone only) in unmated progesterone-treated heifers (Bergfelt et al., 1991). Results of early studies using laparotomy in ewes (Dutt \& Casida, 1948; Ginther, 1971) and transrectal palpation in heifers (Ulberg et al., 1951a) are also consistent with a suppressive relationship between progesterone concentration and follicle development.

In a recent study (Adams et al., 1992), a functional relationship between surges in circulating concentrations of follicle-stimulating hormone (FSH) and the emergence of follicular waves was observed. Wave emergence was detected 1 to 2 days after a significant surge in FSH, and advancing or delaying the surge, using follicle cautery or follicular fluid treatment, was associated with an equivalent advance or delay in wave emergence. The effect of progesterone on this relationship has not been investigated.

The present study examined the relationship between circulating progesterone concentration and the growth of the dominant follicle. Two hypotheses were tested: (i) that greater growth of the dominant follicle of wave 1, compared with that of subsequent anovulatory waves, is due to lower circulating concentrations of progesterone during its growing phase (Expt 1); and (ii) that exposure to low circulating concentrations of progesterone at the end of the growing phase of the anovulatory dominant follicle of wave 1 results in continued follicle growth and prolonged maintenance (Expt 2). The effect of progesterone on the association between FSH and follicular development was also investigated.

\section{Materials and Methods}

Nulliparous Holstein heifers, 1.5-2.5 years of age and weighing $350-650 \mathrm{~kg}$, were used from July to September. Transrectal ultrasonic examinations of the reproductive tract were performed, as previously described (Pierson \& Ginther, 1988), by a single operator using a real-time, B-mode scanner equipped with a $7.5 \mathrm{MHz}$ linear-array transducer (Aloka 210 DX, Corometrics Medical Systems Inc., Wallingford, CT, USA). The heifers were examined once a day; initially to detect ovulation (day 0 ) and thereafter to identify individually and measure follicles $\geqslant 4 \mathrm{~mm}$ as previously described (Knopf et al., 1989). Examinations were done without knowledge of treatment groups. The retrospectively identified dominant follicle of a wave was defined as the one that reached the largest diameter, and subordinate follicles were defined as those that appeared to originate from the same follicular pool as the dominant follicle (Knopf et al., 1989). Total number of follicles $\geqslant 4 \mathrm{~mm}$ was also determined using all detected follicles regardless of whether they were individually identified. 


\section{Experiment 1}

Heifers were randomized in replicate and assigned to a progesterone-treated group $(n=6)$ or a control group $(n=6)$. Progesterone-treated heifers received decreasing doses of progesterone in safflower oil vehicle by subcutaneous injection from day 0 to day 5 . The daily dose of $150,150,100,75,50$ or $25 \mathrm{mg}$, respectively, was divided and given at 12 -h intervals. Control heifers were injected subcutaneously with an equivalent volume $(0.5-1.5 \mathrm{ml})$ of safflower oil vehicle using the same schedule. Ovaries were examined ultrasonically from day 0 to day 15 . A blood sample was collected every $12 \mathrm{~h}$ from day 0 to day 15 ; samples were taken immediately before treatment on days 0 to 5 .

\section{Experiment 2}

Heifers were randomized in replicate and assigned to a group ( $n=6$ per group) receiving a low $\left(30 \mathrm{mg} \mathrm{day}^{-1}\right)$, medium $\left(150 \mathrm{mg} \mathrm{day}^{-1}\right)$, or high $\left(300 \mathrm{mg} \mathrm{day}^{-1}\right)$ dose of progesterone. It was anticipated that the medium dose would simulate the concentrations of endogenous progesterone characteristic of mid-dioestrus (Bergfelt et al., 1991) and hereafter is referred to as the physiological dose. Statistical comparison with mid-luteal-phase progesterone concentrations in the control group of Expt 1 was used to confirm that physiological concentrations were achieved. The low and high doses were chosen to induce lower than physiological and higher than physiological concentrations of progesterone, respectively. Luteolysis was induced at the beginning of treatment to minimize the variability introduced by endogenous progesterone secretion. The daily dose of progesterone (in safflower oil) was divided and given subcutaneously every $12 \mathrm{~h}$ from day 6 to day 20 . All heifers received $25 \mathrm{mg}$ of prostaglandin $\mathrm{F}_{2 a}$ (Lutalyse: The Upjohn Company, Kalamazoo, MI, USA) by intramuscular injection on day 6 immediately before the initial progesterone treatment. Ovaries were examined ultrasonically from day 0 to the next ovulation. A blood sample was collected every $12 \mathrm{~h}$ from day 6 to the day of the next ovulation; samples were taken immediately before treatment.

\section{Assays}

Blood was collected into heparinized tubes from the tail vein and kept in ice-water until centrifugation. Occasional samples $(<5 \%)$ were collected from the jugular vein after unsuccessful attempts were made from the tail vein. Within $1 \mathrm{~h}$ of collection, samples were centrifuged for $15 \mathrm{~min}$ at $1500 \mathrm{~g}$ and plasma was aspirated and stored in a freezer at $-20^{\circ} \mathrm{C}$. Plasma concentrations of progesterone: were determined using a solid-phase ${ }^{125} \mathrm{I}$-radioimmunoassay kit for progesterone (Coat-a-Count Progesterone: Diagnostic Products Corporation, Los Angeles, CA, USA), which has been validated for cattle (Peter \& Bosu, 1987). Progesterone was measured only in the morning sample for each day. Over five assays, the within-assay coefficient of variation was $5.9 \%$ for pooled plasma collected from two heifers during dioestrus, and the between-assay coefficient of variation was $10 \%$. Plasma concentrations of FSH were determined by radioimmunoassay as previously described (Bolt \& Rollins, 1983; Adams et al., 1992), using reagents kindly provided by the USDA Animal Hormone Program. The minimum detectable concentration of USDA-bFSH-B-1 was $0.7 \mathrm{ng}$ per tube $\left(3.5 \mathrm{ng} \mathrm{ml}^{-1}\right)$. Within- and between-assay coefficients of variation were 9 and $15 \%$, respectively.

\section{Statistical analyses}

Single-point measurements (e.g. maximum diameter of the dominant follicle) were examined for a group effect by analysis of variance. End points involving repeated measurements over time (e.g. follicle diameters, hormone concentrations) were examined by split-plot analysis of variance (Gill \& Hafs, 1971) to determine the main effects of time and group and the time $\times$ group interaction. If the group effect or the time $\times$ group interaction was significant, Student's $t$ tests (Expt 1) or the method of least-significant difference (Expt 2) was used to determine where differences occurred among groups within days. The day of emergence of a follicular wave was defined as the day the dominant follicle was identified retrospectively at a diameter of 4-5 mm (Ginther et al., 1989c). For statistical analyses and preparation of figures, follicle data for each wave were normalized to begin on the mean day of emergence of the wave. The FSH concentrations and the number of follicles detected per day for each heifer were normalized according to the follicle diameter data for the corresponding day, i.e. data for these end points were begun on the mean day of emergence of each wave; however, the data for the 4 days before the emergence of each wave were included. Progesterone data were started on the first day of treatment (day 0, Expt 1; day 6, Expt 2) and were continued to day 15 (Expt 1) or normalized to the mean day of the next ovulation (Expt 2).

\section{Results}

\section{Experiment 1}

The mean plasma progesterone concentration was greater $(P<0.01)$ and the maximum diameter of the dominant follicle was smaller $(P<0.04)$ for the progesterone-treated group than for the control group (Table 1). Other discrete end points were not significantly different (Table 1). 
Table 1. Effects of a decreasing dose of progesterone over days 0 to 5 (ovulation $=$ day 0 ) on follicular end points of waves 1 and 2 in heifers (mean \pm SEM)

\begin{tabular}{lcc}
\hline End point & $\begin{array}{c}\text { Control } \\
(n=6)\end{array}$ & $\begin{array}{c}\text { Progesterone-treated } \\
(n=6)\end{array}$ \\
\hline $\begin{array}{l}\text { Mean plasma progesterone during } \\
\text { treatment period }\left(\mathrm{ng} \mathrm{ml} \mathrm{m}^{-1}\right)\end{array}$ & $1 \cdot 7 \pm 0 \cdot 3^{\mathrm{a}}$ & $5 \cdot 2 \pm 0 \cdot 5^{\mathrm{b}}$ \\
$\begin{array}{l}\text { Day of emergence of } \\
\text { wave 1 } \\
\text { wave 2 }\end{array}$ & $-0 \cdot 2 \pm 0 \cdot 2$ & $-0 \cdot 2 \pm 0 \cdot 3$ \\
$\begin{array}{l}\text { Dominant follicle of wave 1 } \\
\text { Maximum diameter }(\mathrm{mm})\end{array}$ & $8 \cdot 8 \pm 0 \cdot 2$ & $8 \cdot 3 \pm 0 \cdot 7$ \\
$\quad \begin{array}{l}\text { Day maximum diameter } \\
\text { attained }\end{array}$ & $15 \cdot 3 \pm 0 \cdot 7^{\mathrm{a}}$ & $12 \cdot 7 \pm 0 \cdot 9^{\mathrm{b}}$ \\
\hline $\mathrm{a}, \mathrm{b}$ Within rows, values with different superscripts are significantly different \\
$(P<0.04)$.
\end{tabular}

Visual and statistical comparisons of the two groups are shown in the day-to-day mean profiles of plasma progesterone and FSH concentrations (Fig. 1), diameter of the dominant follicle and number of detected follicles $\geqslant 4 \mathrm{~mm}$ (Fig. 2). There was a significant group $\times$ day interaction $(P<0.05)$ for circulating concentrations of progesterone and FSH (Fig. 1). The main effect of group was significant $(P<0.03)$ for the diameter of the dominant follicle of wave 1 (progesteronetreated group, $9.7 \pm 0.03 \mathrm{~mm}$ versus control group, $11.8 \pm 0.3 \mathrm{~mm}$; Fig. 2). There was a tendency $(P \leqslant 0 \cdot 1)$ for a group $\times$ day interaction for the diameter of the dominant follicle of wave 2 and the number of follicles detected during wave 2 (Fig. 2).

\section{Experiment 2}

One heifer in the group receiving the medium dose failed to ovulate at the outset of the experiment and was excluded. One heifer in the low-dose group ovulated on day 9 ( 3 days after prostaglandin treatment) and one heifer in the high-dose group failed to ovulate by the end of the observation period (day 60; five follicular waves); their data were not used to calculate the mean interovulatory interval or mean number of interovulatory follicular waves, but were included in the rest of the analyses.

Analysis of the mean daily plasma progesterone concentration between days 6 and day 15 showed no difference $(P<0.3)$ between the control group in Expt $1\left(7.9 \pm 0.4 \mathrm{ng} \mathrm{ml}^{-1}\right)$ and the medium-dose group in Expt $2\left(7.0 \pm 0.4 \mathrm{ng} \mathrm{ml}^{-1}\right)$. By preplanned definition, the medium dose was accepted as approximating mid-luteal phase concentrations of plasma progesterone and is referred to as the physiological dose. Regarding mean circulating concentrations of progesterone (Fig. 3), the main effects (group and day) and their interaction were significant $(P<0.0001)$. Progesterone concentrations, averaged over the interovulatory interval, were different $(P<0.01)$ between all groups; concentrations were highest $\left(9 \cdot 3 \pm 0.4 \mathrm{ng} \mathrm{ml}^{-1}\right)$, intermediate $\left(5.4 \pm 0.3 \mathrm{ng} \mathrm{ml}^{-1}\right)$, and lowest $\left(1.9 \pm 0.2 \mathrm{ng} \mathrm{ml}^{-1}\right)$ in the respective treatment groups. The deviation from physiological concentrations $(P<0.05)$ occurred 3 and 4 days after the start of treatment in the low- and high-dose groups, respectively, and was maintained throughout the treatment period (Fig. 3). The time required to reach the nadir in plasma progesterone concentration after cessation of treatment was directly related to the dose. Ovulation was inhibited until shortly after the nadir. Hence, the interovulatory interval was longest, intermediate and shortest for the high-, physiological- and low-dose groups, respectively $(P<0.05$; Table 2$)$. There was a corresponding effect on the number of follicular waves during the interovulatory interval; the most, intermediate and the fewest number of waves occurred in the high-, physiological- and low-dose groups, respectively, $(P<0.05$; Table 2). 

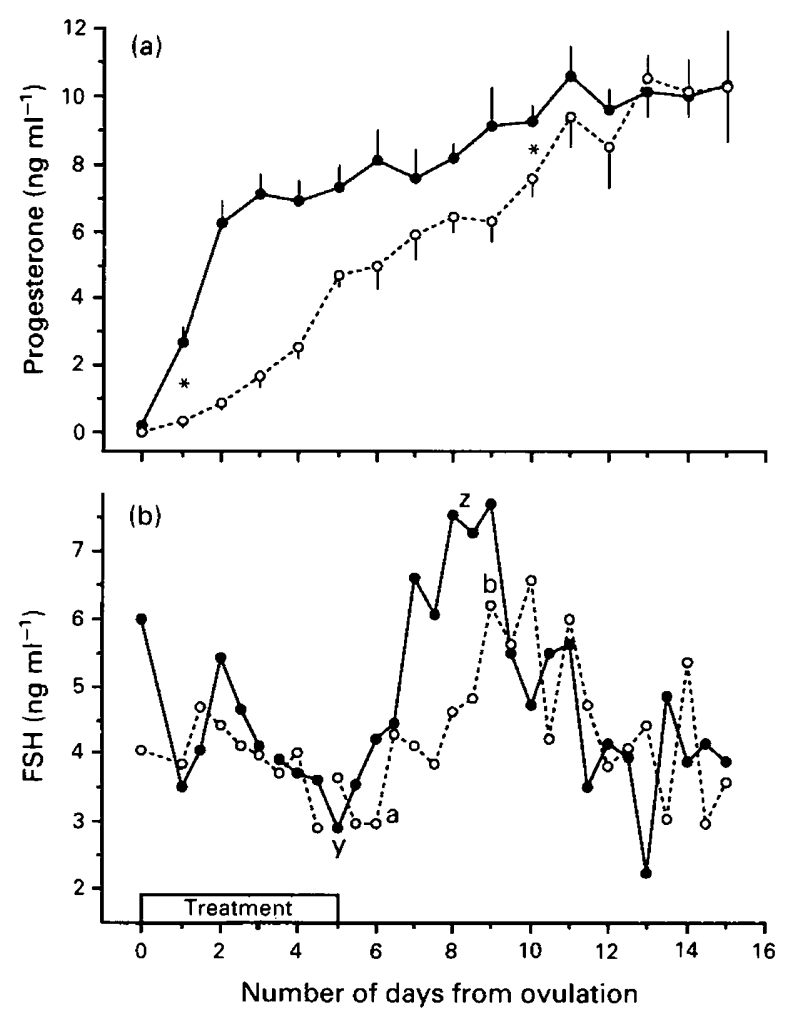

Fig. 1. Circulating concentrations of (a) progesterone and (b) follicle-stimulating hormone (FSH) in heifers treated with a decreasing dose of progesterone $(-, n=6)$ from day 0 to day 5 (ovulation $=$ day 0 ) and in control heifers $(---, n=6$ ). SEM is indicated, by vertical bars, for progesterone; for FSH, the SEM ranged from \pm 0.6 to $\pm 2.2 \mathrm{ng} \mathrm{ml}^{-1}$. (a) Group effect, $P<0.01$; day effect, $P<0.0001$; group $\times$ day interaction, $P<0 \cdot 0001$; $*$ first and last days of significant difference $(P<0.05)$ between groups. (b) Group effect, not significant; day effect, $P<0.0001$; group $\times$ day interaction, $P<0.05$; within each group, means with different superscripts are significantly different $(P<0 \cdot 05)$.

The diameter of the dominant follicle of wave 1 (Fig. 4), averaged over all days, was greater $(P<0.0001)$ for the low-dose group than for the physiological- and high-dose groups $(15.8 \pm 0.4$, $11.0 \pm 0.3$ and $10.3 \pm 0.3 \mathrm{~mm}$, respectively). Day 9 was the first day of a difference $(P<0.05)$ in the diameter of the dominant follicle of the low-dose group compared with either of the other two groups. The diameter of the dominant follicle of wave 2 (Fig. 4), averaged over all days, was greater $(P<0.05)$ for the physiological-dose group than for the high-dose group $(9.6 \pm 0.3$ and $8.3 \pm 0.3 \mathrm{~mm}$, respectively). The maximum diameter of the dominant follicle of wave 1 was greater $(P<0.05)$ in the low-dose group than in the physiological-dose group, and that of wave 2 was greater $(P<0.05)$ in the physiological-dose group than in the high-dose group (Table 2$)$. The day of emergence of wave 2 was later $(P<0.05)$ in the low-dose group than in either of the other two groups (Table 2). The data and results of statistical analyses for all other discrete end points are shown in Table 2.

In the physiological-dose group, the diameter of the dominant follicle averaged over days was greater $(P<0.05)$ for wave 1 than for wave 2 (Fig. 4). Similarly, in the high-dose group, dominant follicle diameter averaged over days was greater $(P<0.05)$ for wave 1 than for wave 2 , and was intermediate for wave 3 (not significantly different from waves 1 and 2). 

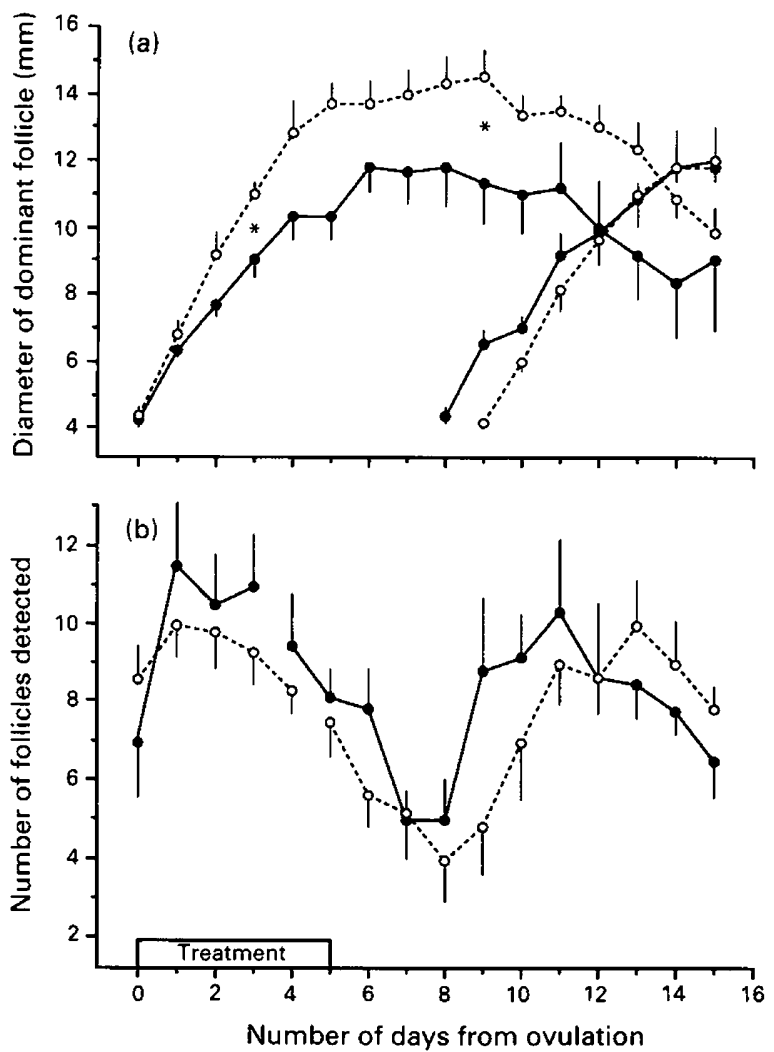

Fig. 2. (a) Diameter profile of the dominant follicle of waves 1 and 2 and (b) the number of follicles ( $\geqslant 4 \mathrm{~mm}$ in diameter) detected (mean \pm SEM) in heifers treated with a decreasing dose of progesterone (,$- n=6$ ) from day 0 to day 5 (ovulation $=$ day 0 ) and in control heifers $(---, n=6)$. (a) Wave 1: group effect, $P<0.03$; day effect, $P<0.0001$; group $\times$ day interaction, not significant. Wave 2: group effect, not significant; day effect, $P<0.0001$; group $\times$ day interaction, $P=0 \cdot 1$. ${ }^{*}$ First and last days of significant difference $(P<0.05)$ between groups. (b) Wave 1: group effect, not significant; day effect, $P<0.0001$; group $\times$ day interaction, not significant. Wave 2: group effect, not significant; day effect, $P<0.0001$; group $\times$ day interaction, $P<0 \cdot 1$.

The mean number of follicles ( $\geqslant 4 \mathrm{~mm}$ in diameter) detected during the observation period was lower $(P<0.02)$ for both the high- $(7.0 \pm 0.3)$ and low- $(6.2 \pm 0.4)$ dose groups than for the physiological-dose group (9.3 $\pm 0 \cdot 4)$ (Fig. 5).

Regarding plasma FSH concentration (Fig. 6), there was no group effect, but there was a day effect $(P<0.02)$ and a group $\times$ day interaction $(P<0.0006)$. The interaction was attributed to an inverse relationship between the low-dose versus physiological-dose groups from days 10 to 16 and days 20 to 26 . Averaged over the interovulatory interval, there was no difference among the high-, physiological- and low-dose groups $\left(13.2 \pm 0.4,10 \cdot 4 \pm 0.2\right.$ and $13.1 \pm 0.3 \mathrm{ng} \mathrm{ml}^{-1}$, respectively).

\section{Discussion}

Administration of progesterone in decreasing doses from day 0 to day 5 was designed to expose early-luteal-phase heifers to mid-luteal-phase concentrations of plasma progesterone and thereby implicated progesterone as the mediator of dominant follicle suppression (Expt 1). In the 
Table 2. Experiment 2: effects of exogenous progesterone (after prostaglandin $F_{2 \alpha}$ treatment on day 6; ovulation $=$ day 0 ) on follicular waves during one interovulatory interval in heifers (mean \pm SEM, number of heifers in parentheses)

\begin{tabular}{|c|c|c|c|}
\hline \multirow[b]{2}{*}{ End point } & \multicolumn{3}{|c|}{ Progesterone dose on days 6 to $20\left(\mathrm{mg} \mathrm{day}^{-1}\right)$} \\
\hline & Low (30) & Physiological (150) & High $(300)$ \\
\hline $\begin{array}{l}\text { Mean plasma progesterone during } \\
\text { treatment period }\left(\mathrm{ng} \mathrm{ml}^{-1}\right)\end{array}$ & $2 \cdot 1 \pm 0 \cdot 2(6)^{\mathrm{a}}$ & $7 \cdot 5 \pm 0 \cdot 3(5)^{b}$ & $12 \cdot 2 \pm 0 \cdot 6(6)^{\mathrm{c}}$ \\
\hline Interovulatory interval (days) & $26 \cdot 2 \pm 1 \cdot 0(5)^{a}$ & $30 \cdot 8 \pm 0 \cdot 6(5)^{b}$ & $40 \cdot 3 \pm 1 \cdot 7(4)^{c}$ \\
\hline $\begin{array}{l}\text { Interval from cessation of treatment to } \\
\text { ovulation (days) }\end{array}$ & $6.2 \pm 1.0(5)^{2}$ & $11 \cdot 0 \pm 0.4(5)^{b}$ & $20 \cdot 3 \pm 1 \cdot 6(6)^{\mathrm{c}}$ \\
\hline Number of follicular waves & $2 \cdot 0 \pm 0 \cdot 0(5)^{a}$ & $2 \cdot 8 \pm 0.2(5)^{b}$ & $3 \cdot 8 \pm 0.3(5)^{\mathrm{c}}$ \\
\hline \multicolumn{4}{|l|}{ Day of emergence of: } \\
\hline Wave 1 & $-0.4 \pm 0.3(6)^{a}$ & $-0 \cdot 2 \pm 0 \cdot 2(5)^{a}$ & $-0 \cdot 2 \pm 0 \cdot 2(6)^{\mathrm{a}}$ \\
\hline Wave 2 & $14 \cdot 8 \pm 1 \cdot 4(5)^{\mathrm{a}}$ & $10 \cdot 0 \pm 1 \cdot 0(5)^{\mathrm{b}}$ & $10 \cdot 0 \pm 0.7(6)^{b}$ \\
\hline Wave 3 & & $17 \cdot 0 \pm 0.4(4)^{a}$ & $17 \cdot 5 \pm 1.0(6)^{\mathrm{a}}$ \\
\hline Wave 4 & & & $28 \cdot 8 \pm 3 \cdot 1(5)$ \\
\hline \multicolumn{4}{|l|}{ Dominant follicle of wave 1} \\
\hline Maximum diameter (mm) & $20 \cdot 8 \pm 1.4(5)^{a}$ & $16 \cdot 2 \pm 1 \cdot 0(5)^{b}$ & $16.0 \pm 0.6(6)^{b}$ \\
\hline Day maximum diameter attained & $10 \cdot 8 \pm 1 \cdot 5(6)^{a}$ & $8.4 \pm 0.7(5)^{\mathrm{a}}$ & $8.0 \pm 0.9(6)^{\mathrm{a}}$ \\
\hline Interval to regression (days)* & $10 \cdot 0 \pm 1 \cdot 4(5)^{a}$ & $7 \cdot 2 \pm 1 \cdot 2(5)^{\mathrm{a}, \mathrm{b}}$ & $5.0 \pm 0.9(6)^{b}$ \\
\hline \multicolumn{4}{|l|}{ Dominant follicle of wave 2} \\
\hline Maximum diameter (mm) & $19 \cdot 6 \pm 1 \cdot 5(5)^{\mathrm{a}}$ & $14 \cdot 8 \pm 1 \cdot 3(5)^{b}$ & $10 \cdot 5 \pm 1 \cdot 0(6)^{\mathrm{c}}$ \\
\hline Day maximum diameter attained & $24 \cdot 0 \pm 1 \cdot 2(5)^{a}$ & $19 \cdot 2 \pm 2 \cdot 2(5)^{\mathrm{a}, \mathrm{b}}$ & $15 \cdot 7 \pm 1.4(6)^{b}$ \\
\hline \multicolumn{4}{|l|}{ Dominant follicle of wave 3} \\
\hline Maximum diameter (mm) & & $20 \cdot 3 \pm 0.8(4)^{a}$ & $14.7 \pm 1.6(6)^{b}$ \\
\hline Day maximum diameter attained & & $29 \cdot 3 \pm 0 \cdot 8(4)^{a}$ & $28 \cdot 0 \pm 2 \cdot 5(6)^{\mathrm{a}}$ \\
\hline
\end{tabular}

${ }^{a, b . c}$ Within rows, values with no common superscripts are significantly different $(P<0.05)$.

*Interval from the day maximum diameter was attained to the start of regression.

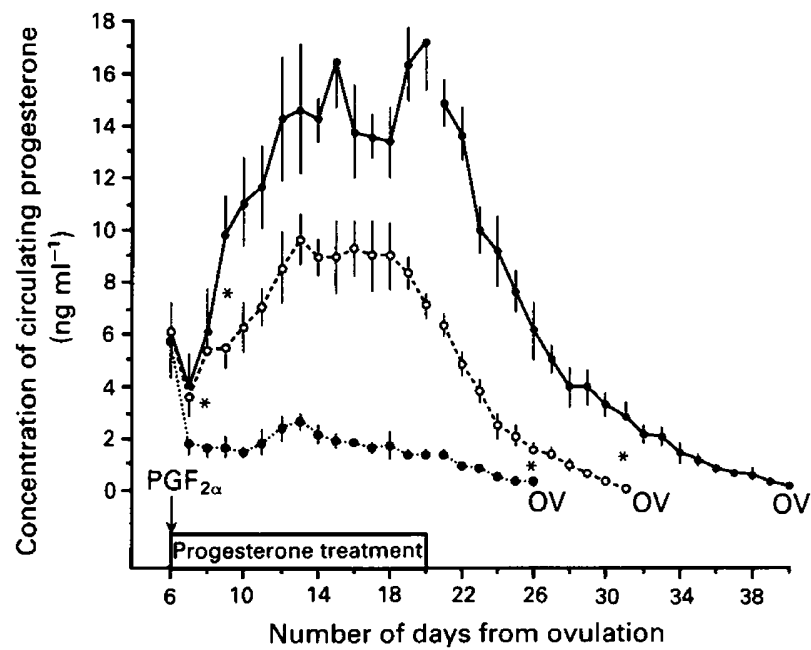

Fig. 3. Circulating concentrations of progesterone during the interovulatory interval in heifers given a luteolytic dose of prostaglandin $\mathrm{F}_{2 \alpha}\left(\mathrm{PGF}_{2 \alpha}\right)$ on day 6 (ovulation $=$ day 0 ) and treated with a low $(\cdots, n=6)$, physiological $(---, n=5)$, or high $(-, n=6)$ dose of progesterone on days 6 to 20 (mean \pm SEM). OV = ovulation. The effects of group and day and the interaction were significant $(P<0.0001)$. ${ }^{*}$ First and last days of significant difference $(P<0.05)$ between groups. 

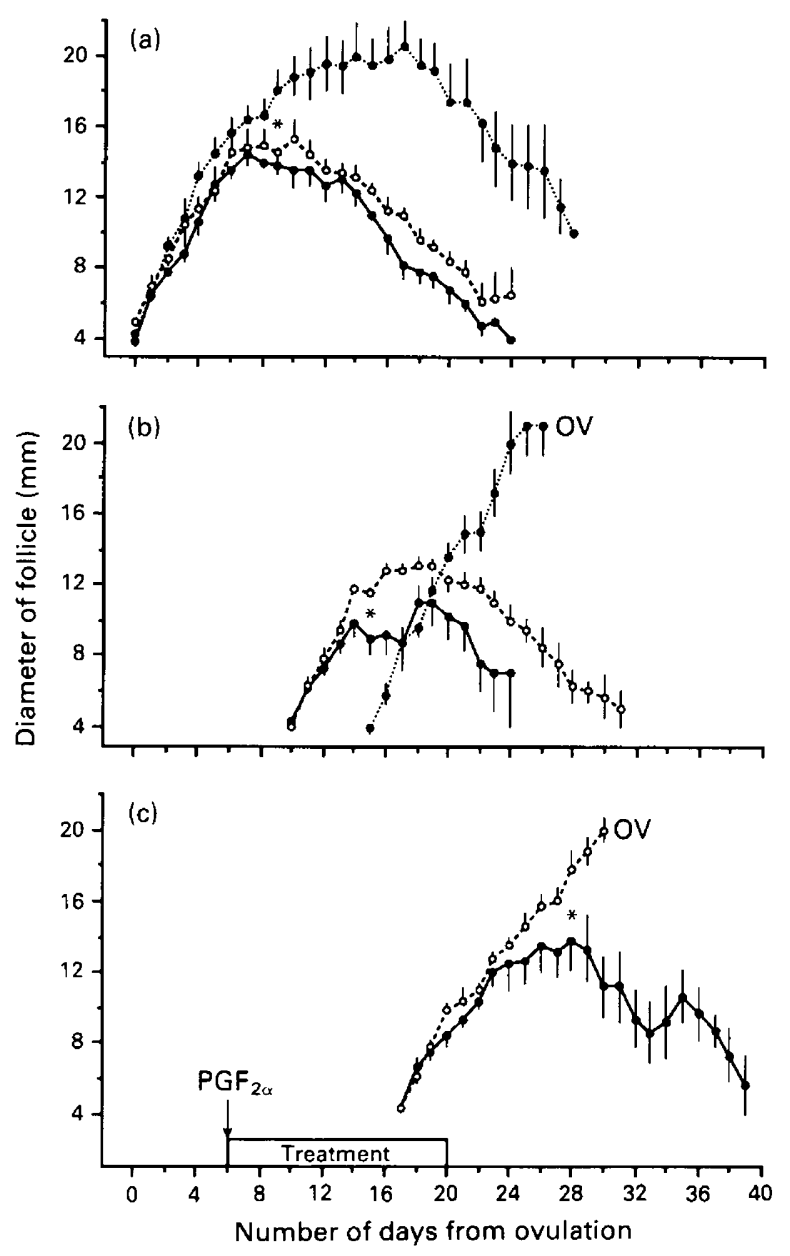

Fig. 4. Diameter profile of the dominant follicle of (a) wave 1, (b) wave 2 and (c) wave 3 in heifers given prostaglandin $\mathrm{F}_{2 \alpha}\left(\mathrm{PGF}_{2 \alpha}\right)$ on day 6 (ovulation = day 0 ) and treated with a low $(\cdots, n=6)$, physiological $(---, n=5)$, or high $(-, n=6)$ dose of progesterone on days 6 to 20 (mean \pm SEM). OV: ovulation. Within each wave, the effect of group and the group $\times$ day interaction were significant $(P<0.002)$. *First day of significant difference $(P<0.05)$ between groups.

progesterone-treated group, plasma progesterone was higher than in the control group by day 1 and was equivalent to, and maintained at, mid-luteal-phase concentrations (days 9-10 in the control group) from day 2 onward. The maximum diameter and the prominence of the diameter profile of the dominant follicle of wave 1 was smaller in the progesterone-treated group than in the control group, thereby supporting the stated hypothesis. The growing phase of the dominant follicle of wave 1 (days 0 to 5 ) in untreated heifers was coincident with the period of luteal gland development and low progesterone concentrations as shown in the control group of Expt 1 (Figs 1 and 2). Conversely, progesterone treatment during the growing phase of wave 1 raised plasma progesterone to concentrations normally occurring during wave 2 and thereby simulated the suppressive effect on the dominant follicle observed during wave 2 in previous studies. These results are consistent with those of an earlier study in ewes, where exogenous progesterone given soon after ovulation depressed the diameter of the largest (marked) follicle (Ginther, 1971). 


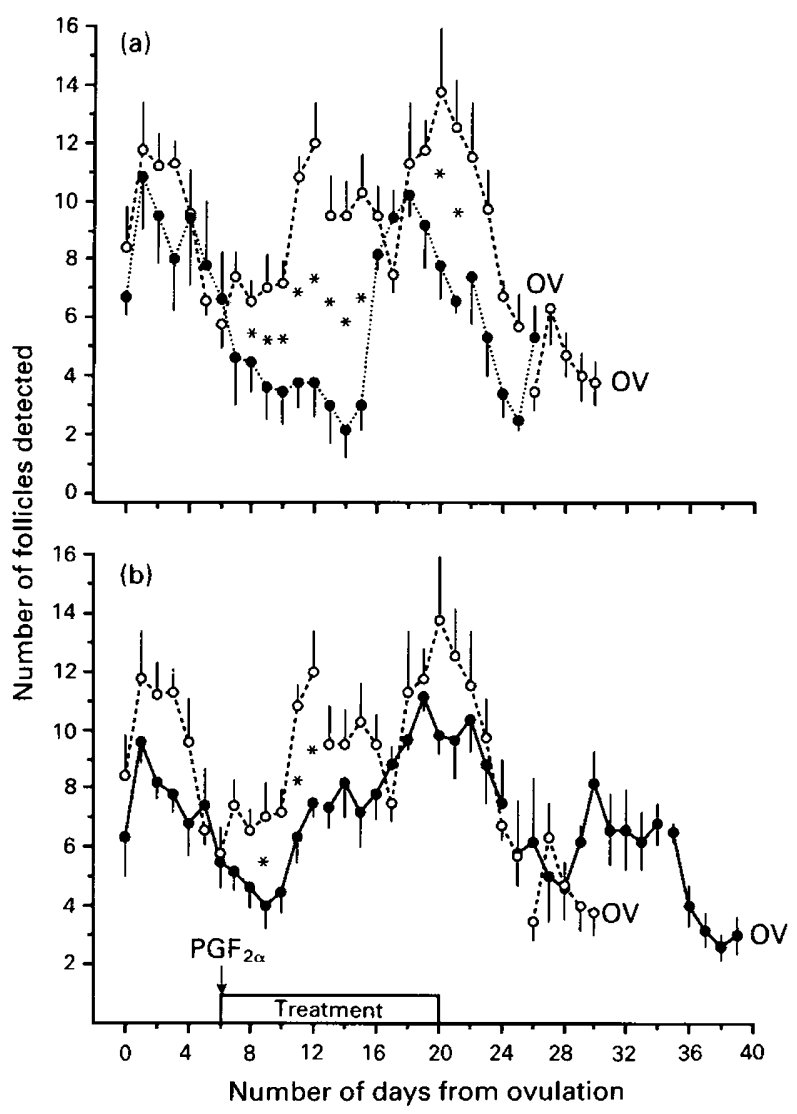

Fig. 5. Number of follicles ( $\geqslant 4 \mathrm{~mm}$ in diameter) detected during the interovulatory interval in heifers given prostaglandin $\mathrm{F}_{2 \alpha}\left(\mathrm{PGF}_{2 \alpha}\right)$ on day 6 (ovulation = day 0 ) and treated with a low $(\cdots, n=6)$, physiological $(---, n=5)$, or high $(-, n=6)$ dose of progesterone on days 6 to 20 (mean \pm SEM). OV: ovulation. (a) Physiological dose versus low dose: group effect, $P<0.04$; day effect, $P<0.0001$; group $\times$ day interaction, $P<0.0001$. (b) Physiological dose versus high dose: group effect, $P<0.05$; day effect, $P<0.0001$; group $\times$ day interaction, $P<0.07$. ${ }^{*}$ Significant differences $(P<0.05)$ between groups.

The experimental design in Expt 2 was successful in achieving higher than normal, near normal and lower than normal mid-luteal-phase concentrations of plasma progesterone by the high

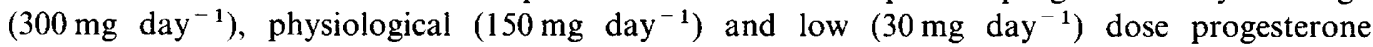
treatments. The prolonged period of decline in plasma progesterone concentration after cessation of subcutaneous injections was not anticipated and was attributed to delayed absorption and metabolism of the safflower oil vehicle.

Results of the present study were consistent with those of previous studies, wherein continued exposure to progesterone (i.e. exogenous: Sirois \& Fortune, 1990; Bergfelt et al., 1991; or during pregnancy: Ginther et al., 1989b) resulted in continued periodic emergence of anovulatory follicular waves. Growth of the dominant follicle of wave 1 was inhibited less by the low dose than by the physiological and high doses; the follicle grew for longer and to a larger diameter and persisted for longer (Fig. 4 and Table 2). Prolonged dominance of this oversized follicle may account for delayed emergence of wave 2 compared with the physiological- and high-dose groups. These results supported the stated hypothesis. Results of a separate study (Sirois \& Fortune, 1990), published after the present study was begun, revealed a similar effect of low circulating concentrations of progesterone on follicular wave development. Maintenance of plasma progesterone between about 

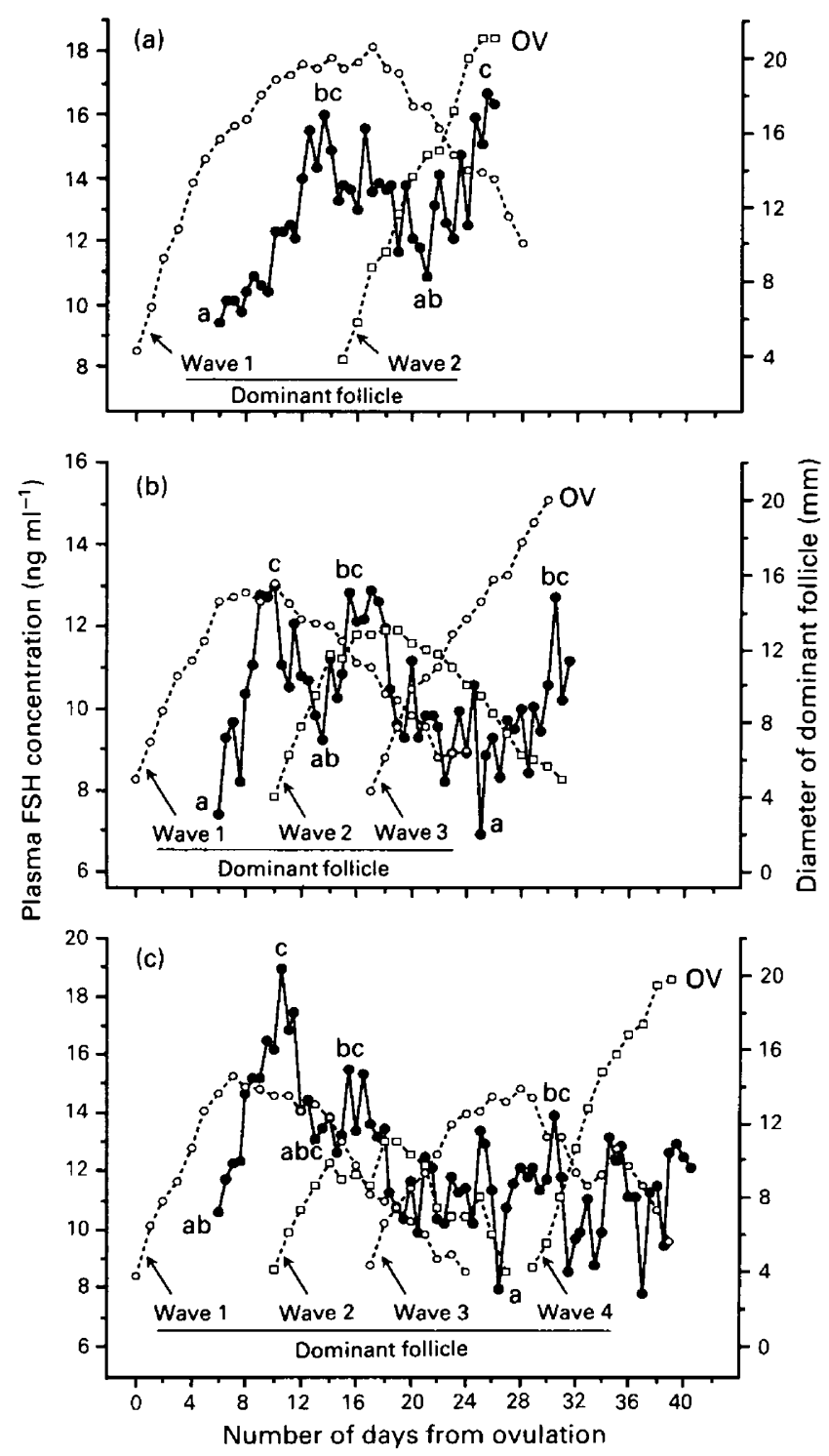

Fig. 6. Circulating concentrations of follicle-stimulating hormone ( $\left.\mathrm{FSH},-{ }_{-}\right)$in association with the diameter of the dominant follicle of successive follicular waves (-- ) during the interovulatory interval in heifers given prostaglandin $\mathrm{F}_{2 \alpha}\left(\mathrm{PGF}_{2 \alpha}\right.$ ) on day 6 (ovulation $=$ day 0 ) and treated with a (a) low $(n=6)$, (b) physiological $(n=5)$, or (c) high $(n=6)$ dose of progesterone on days 6 to 20 (SEM for FSH ranged from \pm 0.5 to \pm 3.3 ). OV: ovulation. Within each group, means with no common superscripts are significantly different $(P<0.05)$. For FSH: group effect, NS; day effect, $P<0.02$; group $\times$ day interaction, $P<0.0006$.

I and $2 \mathrm{ng} \mathrm{ml}^{-1}$, by insertion of a single progesterone-releasing intravaginal device, promoted the prolonged growth of the dominant follicle and was associated with a complete absence of follicle recruitment.

In Expt 2, the high-dose progesterone treatment did not suppress the dominant follicle of wave 1 more than the physiological dose (Fig. 4); however, treatment was begun on day 6, which has been reported as the approximate end of the growing phase and the start of the static phase of the 
dominant anovulatory follicle (Ginther et al., 1989a). The high dose of progesterone did, however, suppress the dominant follicle of wave 2 compared with the physiological dose (Fig. 4 ). The effect was attributable to exposure of the dominant follicle of wave 2 to high progesterone concentrations during its growing phase. The dominant follicle of wave 2 grew for a shorter period, reached a smaller diameter, and regressed sooner in the high-dose group compared with that of the physiological-dose group. In both the high- and physiological-dose groups, the diameter profile of the dominant follicle of wave 1 was more prominent than that of wave 2 . Again, the suppressive effect was attributable to exposure to high progesterone concentrations during the growing phase of the dominant follicle. Results demonstrated that progesterone, when administered during the growing phase, inhibited the dominant follicle in a dose-dependent manner. The effect on wave 2 in Expt 2 is consistent with the effect on wave 1 in Expt 1; i.e. low concentrations of progesterone during the growing phase were associated with enhanced follicular growth, whereas high concentrations of progesterone were associated with suppressed growth.

The oversized dominant follicle of wave 1 in the low-dose group in the present study would have been considered a pathological follicular cyst because of its size and persistence for more than 10 days in the absence of a corpus luteum (Kesler \& Garverick, 1982; Cook et al., 1990). The possible role of progesterone-induced suppression of $\mathrm{LH}$ was hypothesized in early studies where low doses of exogenous progesterone were associated with follicular cyst formation in cattle (Christian \& Casida, 1948; Ulberg et al., 1951 a), sheep (Dutt \& Casida, 1948) and pigs (Ulberg et al., 1951b); but concentrations of $\mathrm{LH}$ were not measured. Basal plasma $\mathrm{LH}$ concentrations did not differ between heifers given one rather than two progesterone-releasing intravaginal devices (Sirois \& Fortune, 1990), but, as in the present study, blood samples were not collected frequently enough to determine the effect of progesterone on LH pulse frequency. However, there is some basis for speculation that progesterone-induced inhibition of LH pulse frequency may be involved in suppressing the growth of the dominant follicle, since circulating concentrations of progesterone have been negatively correlated with LH pulse frequency (Ireland \& Roche, 1982; Schallenberger et al., 1985; Glencross, 1987; Roberson et al., 1989). In this regard, low-level progesterone exposure (and therefore less inhibition of $\mathbf{L H}$ ), at the time the dominant follicle normally stops growing, may be a fundamental component in the aetiology of ovarian follicular cysts. In addition to the oversized anovulatory follicle observed in Expt 2, the mean diameter of the ovulatory follicle on the day before ovulation also appeared oversized $(\geqslant 20 \mathrm{~mm})$ compared with that of previous studies (16 mm; Ginther et al., 1989a, b). The prolonged growing phase of the ovulatory follicle was temporally associated with the period of low and slowly declining plasma progesterone concentrations after the cessation of treatment (Figs 3 and 4). Further studies, using more frequent plasma sampling, will be needed to address the hypothesis that increased LH pulse frequency, as a result of low circulating concentrations of progesterone, is responsible for promoting continued growth and prolonged maintenance of the dominant follicle.

Progesterone has been shown to have a pronounced negative effect on secretion of FSH from dispersed ovine pituitary cells in vitro (Batra \& Miller, 1985; Phillips et al., 1988), but a negative effect has not been observed in vivo. Consistent with the results reported here, previous studies involving exogenous progesterone treatment in cattle (Roche \& Ireland, 1981; Ireland \& Roche, 1982; Schoenemann et al., 1985; Bolt et al., 1990) and sheep (Goodman et al., 1981; Martin et al., 1988; McNatty et al., 1989) have failed to show any direct effect (suppressive or augmentative) on circulating FSH. In the present study, progesterone appeared to affect circulating FSH indirectly through its effect on the dominant follicle. Results indicated that progesterone imposed its suppressive effects on the dominant follicle only during the growing phase and not during the static and regressing phases. Support for these conclusions was found in the following results from Expts 1 and 2.

In Expt 1, the group $\times$ day interaction for circulating FSH concentration (Fig. 1) and the tendencies for an interaction for the diameter profile of the dominant follicle of wave 2 and the number of follicles detected per day (Fig. 2) were attributed to an advance of 1-2 days in the 
pattern of change for each end point in the progesterone-treated group compared with the control group. The recent report of a relationship between surges of FSH and the emergence of follicular waves (Adams et al., 1992) demonstrated that a surge in circulating FSH was responsible for, and necessarily preceded, the emergence (first day of ultrasonic detection of 4 or $5 \mathrm{~mm}$ follicles) of a follicular wave. In Expt 1, progesterone-induced suppression of the dominant follicle of wave 1 abbreviated the period of dominance and thereby hastened the second FSH surge; this, in turn, resulted in earlier emergence of wave 2.

In Expt 2, high plasma progesterone concentration was not associated with reduced mean FSH concentration (no difference among groups), but the pattern of the FSH profile was altered. The peak in the FSH surge was delayed by about 4 days in the low-dose versus the physiological-dose group (day 13 versus day 9) resulting in a corresponding delay in the emergence of wave 2 (mean day 10.0 versus day 14.8; Table 2 ). This is consistent with the concept that the dominant follicle suppresses its subordinates and delays the emergence of the next wave (Kastelic et al., 1990; Ko et al., 1991) by suppressing circulating FSH (Adams et al., 1992). The delay in emergence of wave 2 resulted from prolonged dominance (prolonged FSH suppression) of the oversized dominant anovulatory follicle of wave 1 in the low-dose group. The suppressive effects on FSH were also reflected in the profile of the number of detected follicles (Fig. 5); numbers of follicles in the lowdose group were suppressed, compared with the physiological-dose group (days 8 to 15), until after the FSH surge, thus explaining, in part, the observed group-by-day interaction. In a recent study (Martin et al., 1991), intrafollicular concentrations of inhibin increased during growth of dominant anovulatory follicles, and increasing inhibin concentrations may have been responsible for the observed effects on FSH in the present study.

In Expt 2, a surge (significant rise from nadir) or an apparent surge (rise not statistically significant) in FSH was observed about 1-2 days before the detected emergence of each wave (Fig. 6). Wave 1 was not considered, since blood was not sampled before day 6 in any group. By estimating the end of the growing phase of each dominant follicle as the last day of significant increase in mean diameter and relating it to the day on which peak FSH concentrations occurred for each treatment group (Fig. 6), the end of the growing phase was followed by a peak in FSH, on average, 3.0 days later (range 1.5 to 5.5 days). These results support the concept (Adams et al., 1992) that, at some point during the static phase, the dominant follicle becomes incapable of suppressing FSH and, thereby, allows FSH to surge and elicit the emergence of the next follicular wave.

The results of Expt 1 supported the hypothesis that the greater development of the dominant follicle of wave 1, compared with subsequent anovulatory waves, is due to lower circulating concentrations of progesterone during its growing phase. The results of Expt 2 supported the hypothesis that exposure to low circulating concentrations of progesterone at the end of the growing phase results in continued growth and prolonged maintenance of the dominant follicle. Collectively, the results of the experiments were consistent with the concept that progesterone suppresses the dominant follicle during its growing phase and that it does so in a dose-dependent manner. The suppressive effects on the dominant follicle were not mediated by reduced circulating FSH, since progesterone treatment did not suppress FSH. High plasma progesterone during follicular growth resulted in a smaller, shorter-lived dominant follicle and an earlier surge in FSH preceding the next follicular wave, and hastened emergence of the next follicular wave. Conversely, low concentrations of progesterone resulted in an oversized persistent dominant follicle, a delayed surge in FSH and delayed emergence of the next wave.

This study was supported by the College of Agricultural and Life Sciences, University of Wisconsin-Madison. We thank The Upjohn Company for providing Lutalyse, D. J. Bolt of the USDA Animal Hormone Program for providing assay reagents, F. Wegner for assistance with the radioimmunoassay procedure, $\mathbf{L}$. Kulick for assistance with graphs and $\mathbf{M}$. Westphal for manuscript preparation. We also thank D. Bergfelt, P. Griffin and J. Kastelic for assistance in data collection. 


\section{References}

Adams, G.P., Matteri, R.L., Kastelic, J.P., Ko, J.C.H. \& Ginther, O.J. (1992) Association between surges of follicle stimulating hormone and the emergence of follicular waves in heifers. Journal of Reproduction and Fertility 94, 177-188.

Batra, S.K. \& Miller, W.L. (1985) Progesterone inhibits basal production of follicle-stimulating hormone in ovine pituitary cell culture. Endocrinology 117, 2443-2448.

Bergfelt, D.R., Kastelic, J.P. \& Ginther, O.J. (1991) Continued periodic emergence of follicular waves in nonbred progesterone-treated heifers. Animal Reproduction Science 24, 193-204.

Bolt, D.J. \& Rollins, R. (1983) Development and application of a radioimmunoassay for bovine follicle-stimulating hormone. Journal of Animal Science 56, 146-154.

Bolt, D.J., Scott, V. \& Kiracofe, G.H. (1990) Plasma LH and FSH after estradiol, norgestomet and Gn-RH treatment in ovariectomized beef heifers. Animal Reproduction Science 23, 263-271.

Christian, R.E. \& Casida, L.E. (1948) The effects of progesterone in altering the estrous cycle of the cow. Journal of Animal Science 7, 540 (Abstract).

Cook, D.L., Smith, C.A., Parfet, J.R., Youngquist, R.S., Brown, E.M. \& Garverick, H.A. (1990) Fate and turnover rate of ovarian follicular cysts in dairy cattle. Journal of Reproduction and Fertility 90, 37-46.

Dutt, R.H. \& Casida, L.E. (1948) Alteration of the estrual cycle in sheep by use of progesterone and its affect upon subsequent ovulation and fertility. Endocrinology 43, 208-217.

Gill, J.L. \& Hafs, H.D. (1971) Analysis of repeated measurements of animals. Journal of Animal Science 33, 331-336.

Ginther, O.J. (1971) Influence of progesterone and number of corpora lutea on ovaries in sheep. American Journal of Veterinary Research 32, 1987-1992.

Ginther, O.J., Kastelic, J.P. \& Knopf, L. (1989a) Composition and characteristics of follicular waves during the bovine oestrous cycle. Animal Reproduction Science 20, 187-200.

Ginther, O.J., Knopf, L. \& Kastelic, J.P. (1989b) Ovarian follicular dynamics in heifers during early pregnancy. Biology of Reproduction 41, 247-254.

Ginther, O.J., Knopf, L. \& Kastelic, J.P. (1989c) Temporal associations among ovarian events in cattle during oestrous cycles with two and three follicular waves. Journal of Reproduction and Fertility 87, 223-230.

Glencross, R.G. (1987) Effects of pulsatile infusion of gonadotrophin-releasing hormone on plasma oestradiol-17 $\beta$ concentrations and follicular development during naturally and artificially maintained high levels of plasma progesterone in heifers. Journal of Endocrinology 112, 77-85.

Goodman, R.L., Pickover, S.M. \& Karsch, F.J. (1981) Ovarian feedback control of follicle-stimulating hormone in the ewe: evidence for selective suppression. Endocrinology 108, 772-777.

Ireland, J.J. \& Roche, J.F. (1982) Effect of progesterone on basal LH and episodic LH and FSH secretion in heifers. Journal of Reproduction and Fertility 64, 295-302.

Kastelic, J.P., Ko, J.C.H. \& Ginther, O.J. (1990) Suppression of dominant and subordinate ovarian follicles by a proteinaceous fraction of follicular fluid in heifers. Theriogenology 34, 499-509.

Kesler, D.J. \& Garverick, H.A. (1982) Ovarian cysts in dairy cattle: a review. Journal of Animal Science 55, 1147-1159.

Knopf, L., Kastelic, J.P., Schallenberger, E. \& Ginther, O.J. (1989) Ovarian follicular dynamics in heifers: test of two-wave hypothesis by ultrasonically monitoring individual follicles. Domestic Animal Endocrinology 6, 111-119.

Ko, J.C.H., Kastelic, J.P., Del Campo, M.R. \& Ginther, O.J. (1991) Effects of a dominant follicle on ovarian follicular dynamics during the oestrous cycle in heifers. Journal of Reproduction and Fertility 91, 511-519.

McNatty, K.P., Hudson, M.L., Collins, F., Fisher, M., Heath, D.A. \& Henderson, K.M. (1989) Effects of oestradiol-17 $\beta$, progesterone or bovine follicular fluid on the plasma concentrations of FSH and LH in ovariectomized Booroola ewes which were homozygous carriers or non-carriers of a fecundity gene. Journal of Reproduction and Fertility 87, 573-585.

Martin, G.B., Price, C.A., Thiéry, J-C. \& Webb, R. (1988) Interactions between inhibin, oestradiol and progesterone in the control of gonadotrophin secretion in the ewe. Journal of Reproduction and Fertility 82, 319-328.

Martin, T.L., Fogwell, R.L. \& Ireland, J.J. (1991) Concentrations of inhibins and steroids in follicular fluid during development of dominant follicles in heifers. Biology of Reproduction 44, 693-700.

Peter, A.T. \& Bosu, W.T.K. (1987) Effects of intrauterine infection on the function of corpora lutea formed after first postpartum ovulation in dairy cows. Theriogenology 27, 593609.

Phillips, C.L., Lin, L.W., Wu, J.C., Guzman, K., Milsted, A. \& Miller, W.L. (1988) $17 \beta$-Estradiol and progesterone inhibit transcription of the genes encoding the subunits of ovine follicle-stimulating hormone. Molecular Endocrinology 2, 641-649.

Pierson, R.A. \& Ginther, O.J. (1988) Ultrasonic imaging of the ovaries and uterus in cattle. Theriogenology 29, 21-37.

Roberson, M.S., Wolfe, M.W., Stumpf, T.T., Kittok, R.J. \& Kinder, J.E. (1989) Luteinizing hormone secretion and corpus luteum function in cows receiving two levels of progesterone. Biology of Reproduction 41, 997-1007.

Roche, J.F. \& Ireland, J.J. (1981) The differential effect of progesterone on concentrations of luteinizing hormone and follicle-stimulating hormone in heifers. Endocrinology 108, 568-572.

Savio, J.D., Keenan, L., Boland, M.P. \& Roche, J.F. (1988) Pattern of growth of dominant follicles during the oestrous cycle of heifers. Journal of Reproduction and Fertility 83, 663-671.

Schallenberger, E., Schöndorfer, A.M. \& Walters, D.L. (1985) Gonadotrophins and ovarian steroids in 
cattle. I. Pulsatile changes of concentrations in the jugular vein throughout the oestrous cycle. Acta Endocrinologica 108, 312-321.

Schoenemann, H.M., Humphrey, W.D., Crowder, M.E., Nett, T.M. \& Reeves, J.J. (1985) Pituitary luteinizing hormone-releasing hormone receptors in ovariectomized cows after challenge with ovarian steroids. Biology of Reproduction 32, 574-583.

Sirois, J. \& Fortune, J.E. (1988) Ovarian follicular dynamics during the oestrous cycle in heifers monitored by real-time ultrasonography. Biology of Reproduction 39, 308-317.

Sirois, J. \& Fortune, J.E. (1990) Lengthening the bovine estrous cycle with low levels of exogenous progesterone: a model for studying ovarian follicular dominance. Endocrinology 127, 916-925.

Trimberger, G.W. \& Hansel, W. (1955) Conception rate and ovarian function following estrus control by progesterone injections in dairy cattle. Journal of Animal Science 14, 224-232.

Ulberg, L.C., Christian, R.E. \& Casida, L.E. (195la) Ovarian response in heifers to progesterone injections. Journal of Animal Science 10, 752-759.

Ulberg, L.C., Grummer, R.H. \& Casida, L.E. (1951b) The effects of progesterone upon ovarian function in gilts. Journal of Animal Science 10, 665 671 .

Received 9 October 1991 